\title{
Nurses' Recognition in Nursing for Patients and Families about Organ Donation after Brain Death, Care for Family Members and Supports for Nurses
}

\author{
Michiyo Andoㅁ, Mika Katahara ${ }^{2}$ \\ ${ }^{1}$ Department of Nursing, Daiichi Pharmacy University, Fukuoka, Japan \\ ${ }^{2}$ St. Mary's Hospital, Kurume, Japan \\ Email:m-ando@daiichi-cps.ac.jp
}

How to cite this paper: Ando, M. and Katahara, M. (2020) Nurses' Recognition in Nursing for Patients and Families about Organ Donation after Brain Death, Care for Family Members and Supports for Nurses. Open Journal of Nursing, 10, 1209-1218. https://doi.org/10.4236/ojn.2020.1012087

Received: November 6, 2020

Accepted: December 20, 2020

Published: December 23, 2020

Copyright $\odot 2020$ by author(s) and Scientific Research Publishing Inc. This work is licensed under the Creative Commons Attribution International License (CC BY 4.0).

http://creativecommons.org/licenses/by/4.0/

\begin{abstract}
Background: Globally, there a problem of disequilibrium between donation and organ transplantation, this equilibrium is remarkable in Japan. Especially there are few donations from brain death, and researches from the view point of nurses in clinical situation were needed. Purpose: The purpose of this study was to clarify the recognition of nurses in organ transplantation nursing, required care for families of patients, and required support for nurses to promote quality of nurses in organ donation. Methods: We conducted this research within 2 months in 2019 in Western Japan. A researcher conducted a semi-qualitative interview for nurses in organ transplantation nursing about their recognition of nursing, required care for family members, and required support for nurses once. Results: Nurses recognized that some family members who knew patients' thoughts made decision easily and some who didn't know had difficulties. Many nurses felt insufficiency for family cares and some confronted ethical problems. Though some nurses felt conflict about their own thoughts or religion, they took care of patients or family members with responsibility. As for care for families, nurses thought practice of care considering families' feeling, support of decision making, and care for family to live positively after transplantation as required care. About support for nurses, nurses required education of transplantation, increase of staff members, chance to share dilemma, and mental care. Discussion: Nurses recognized the importance of decision making, and felt an insufficiency for family care or dilemmas. To propose high quality of nursing and organ donation or transplantation, education about transplantation including family care, management about resolution of dilemma or mental health may be required.
\end{abstract}




\section{Keywords}

Brain Death, Organ Donation, Nurse, Recognition, Family Care

\section{Introduction}

Organ and tissue transplants have been lifesaving procedures for patients experiencing end-stage organ failure [1]. It is well known that the demand for organs exceeds the supply of donors worldwide. The revised organ transplant law in 2010 in Japan has allowed the deceased family to provide written consent for the removal of an organ if the intention of the deceased is unknown. The rate of organ transplantation in America is 33.3 per every 100 million, and 8.66 in Korea, but only, 0.77 in Japan [2]. This shows that the rate in Japan is very low. In addition to this, the rate of organ transplantation from brain death is fewer than that of a living body transplant like a kidney. Although nurses in the ICU (Intensive Care Unit) get involved in nursing care in transplantation, chance to learn about nursing is very few.

Laughlin, Neukirchinger, Monks [3] investigated the differences in organ donation consent outcome of a new nursing role (specialist requesters) and existing nursing role (specialist nurse in organ donation). Although specialist requesters asked family members about organ donation especially to promote understanding it, its role was not clear comparing with existing special nurse. This study suggests importance of explanation about donor consent or decision making. Jawoniyi, Gormley, McGleenan, et al. [4] examined awareness and roles of healthcare professionals as a systematic literature review. They said that the global organ shortage is neither contingent upon unavailability of suitable organ nor exclusively depends upon healthcare professionals. There are a lot of factors and healthcare professionals' role, knowledge awareness, and so on which might impact upon the organ donation and transplantation process. O'Leary [5] showed assessment criteria which critical nurse must use to refer a patient to the organ procurement organization. Also that article discussed the significance of empathy and cultural competency in conversations with a patient's family. These studies were questionnaire researches or review articles, and interviews or qualitative studies are few.

In Japan, Nagano and Kamizato [6] clarified difficulties of nurses in organ donation under brain death or heart death, such as "Confusion due to lack of nursing experience and feelings of insufficiency" and "Anxiety and pain". However, they suggested that they had to separate the cases in brain death and heart death. Also, Hayashi, Tanimizu, Akazawa, et al. [7] investigated ethical distress in organ transplantation like the wavering of faith in organ transplantation due to differences in opinion with others as well as experience with cases involving an unpromising treatment. Since this study included both donors and recipients, care for each position was complicated. And this study was only one case study. 
Kawakubo et al. of a literature review study [8] showed that the number of organ transplantation may increase a little by little, but the number of research in Japan was very few. They suggested the importance of an increase in research about organ donation nursing. We thought that we needed a qualitative study by an interview style from the view of nurses to promote the quality of nursing in organ transplantation focusing on donation after brain death.

\section{Purpose}

The purpose of this study was to clarify the thoughts of nurses concerning organ donation under brain death, and the required care for the donors' family members and required supports for the nurses involved.

\section{Method}

\subsection{Participant}

The participants were 5 nurses who took care of patients and their family members in an ICU unit for the last 5 years in a General Hospital (Table 1). A head nurse chose candidates as participants, and the researchers got in touch with them after obtaining permission. The inclusion criteria were to select nurses involved in organ donation directly under brain death. The exclusion criteria were to exclude nurses to whom the interview might be a burden.

\subsection{Procedure and Data Analysis}

We conducted this research within 2 months in 2019 in Western Japan. Interview data was recorded with permission of participants in a private room. To progress nursing care in organ transplantation, we prepared these three questions: "what did you feel and think about nursing", "what care is required for the family", and "what support is required for these nurses", with participants' permission, their narratives were recorded on IC recorders. Each interview lasted about 60 minutes. This study was approved by the ethical boards of both St. Mary's College and St. Mary's Hospital.

We conducted qualitative analysis. For the narrative data, we employed "qualitative analysis" by Tanizu [9], which involved creating codes, subcategories and categories. These narratives were edited into the shortest statement without losing meaning and coded into one subcategory along with similar statements.

Table 1. Background of participants.

\begin{tabular}{lcccc}
\hline & Gender & Age & Yeas as nurses experience & Years as nurses in ICU \\
\hline ID1 & Female & 40 & 22 & 2 \\
ID2 & Male & 20 & 6 & 3 \\
ID3 & Female & 30 & 10 & 7 \\
ID4 & Female & 50 & 28 & 2 \\
ID5 & Female & 20 & 3 & 1 \\
\hline
\end{tabular}


Similar subcategories were then integrated into one category. To maintain reliability, categorization and coding were validated independently by researchers. Inconsistencies were discussed and negotiated until an agreement was reached.

\section{Results}

\section{1) Recognition of nurses in organ transplantation after brain death (Table} 2)

Table 2. Recognition of nurses for organ donation.

\begin{tabular}{|c|c|c|}
\hline Code & Subcategory & Category \\
\hline \multicolumn{3}{|l|}{ Thoughts about decision making of family members } \\
\hline $\begin{array}{l}\text { - Family members remember that their loved one want to } \\
\text { remain useful to others. } \\
\text { - Family members imagined that a loved one would require } \\
\text { organ donation. }\end{array}$ & $\begin{array}{l}\text { - Family members remembered loved one's way of } \\
\text { living. } \\
\text { - Family member spoke about their loved one's feeling. }\end{array}$ & $\begin{array}{l}\text { - Family's decision to } \\
\text { respect the way of } \\
\text { living }\end{array}$ \\
\hline $\begin{array}{l}\text { - Family members tried to find signs on their driving license. } \\
\text { - Family members asked a nurse what they would do if they } \\
\text { were in the same situation. } \\
\text { - Family members had difficulty making decisions for a few } \\
\text { days. }\end{array}$ & $\begin{array}{l}\text { - Family member didn't know loved one's intention } \\
\text { about donation. } \\
\text { - Family members unknown reliance of judgement } \\
\text { - Family members had difficulty making decisions. }\end{array}$ & $\begin{array}{l}\text { - Suffering of family } \\
\text { members in decision } \\
\text { making }\end{array}$ \\
\hline $\begin{array}{l}\text { - A family member denied to donate a loved one's eyes, } \\
\text { because we need eyes to see what we face in the world. } \\
\text { A family said that they could not stand the corpse without }\end{array}$ & $\begin{array}{l}\text { - Family member was thinking about the world. } \\
\text { - Family member thought the face in the coffin as } \\
\text { importance. }\end{array}$ & $\begin{array}{l}\text { - Influence of culture on } \\
\text { the decision making of } \\
\text { body parts }\end{array}$ \\
\hline
\end{tabular}
eyes.

\section{Thoughts about practical nursing in clinical situation}

- Nurses couldn't talk with family members.

- Nurses couldn't correspond to family members well.

- Nurses couldn't read feeling of family members when the story for donation didn't go on.

- Nurses hesitated to get involved with family members since they couldn't understand their feeling.

- Family's care is difficult when the donation didn't go on.

- Nurses had ethical questions about direction in hurry for transplantation.

- A nurse said to a doctor that it seemed to be rushed.

- A nurse had ethical problem in atmosphere for improving transplantation.

- A nurse stated her opinion to the doctor about donation.

- Family members were relieved after a donation operation. - A family was relieved after donation operation safely

- A husband shed tears saying that she was "cold" when he touched his wife's hand.

- A family member realized a loved one's death feeling cold.

\section{Thoughts about nursing or nurses}

- Nurses didn't know how to get involved in a team though a coordinator and a doctor discussed.

Contents or roles were not clear in the beginning of transplantation.

- Nurses recorded facial expression or feelings for a loved - Nurses in transplantation team searched their roles. one.

- A nurse felt resistance since she had her own faith.

- A nurse tried to practice the best care even if a nurses' faith was different.

- A nurse was glad to be in charge for a donner and a family.

- A nurse had a sense of fulfillment about being useful.

- We need to stop medication at times.

- A nurse though thow she welcomed death being herself.
- Some nurses had opposite opinion for transplantation.

- Nurses took responsibility as a nurse though the though was opposite for transplantation.

- A nurse was interested in transplantation nursing which save lives.

- A nurse had a sense of fulfillment about being useful.

- A nurse felt limitation of medication in a certain point.

- A nurse thought of their last period.
Feeling of insufficiency for family care.

- Nurses confronting ethical problems

- Complicated feelings compounded by relief and sadness

- Seeking nursing in the transplantation team

- Taking responsibility while feeling conflict

- Positive attitude toward

- nursing in transplantation

- Deepening of the view of nurses' life and death 
We chose categories about recognition and observing them, we found separated into three themes: [Thoughts about decision making of family members], [Thoughts about practical nursing in clinical situation], and [Thoughts about nursing or nurses].

For the theme of [Thoughts about the decision making of family members], categories like the "Family's decision to respect the way of living", "Suffering of family members in decision making", and "Influence of culture on the decision making of body parts", were chosen. These categories showed that some families made decision making easily, and some didn't easily. Culture also influence on decision making.

For the theme of [Thoughts about practical nursing in a clinical situation], "Feeling of insufficiency for family care", "Nurses confronting ethical problems", and "Complicated feelings compounded by relief and sadness" were chosen. That is, some nurses felt insufficiency for family care, although family had complicated feelings, and sometimes nurses felt ethical problems in clinical scene.

For the themes of [Thoughts about nursing or nurses], "Seeking nursing in the transplantation team", "Taking responsibility while feeling conflicted", "Positive attitudes toward nursing in transplantation", and "Deepening of the view of nurses' life and death" were chosen. There were few nurses who experienced organ donation and they sought nursing from experiences. Some nurses felt conflicts, but some had positive attitude.

\section{2) Required care for family members of patients (Table 3)}

Nurses felt the importance of nursing care, such as the "Practice of care in consideration of the families' feelings". Moreover, they thought understanding family member's indecisiveness was important, such as "Support for decision

Table 3. Requirement for family care in organ donation.

\begin{tabular}{|c|c|c|}
\hline Code & Subcategory & Category \\
\hline $\begin{array}{l}\text { - A nurse couldn't listen to the most difficult matters of } \\
\text { family members. } \\
\text { - A nurse needs to listen to family members' disappointed } \\
\text { feeling when donation was stopped. }\end{array}$ & $\begin{array}{l}\text { - A nurse needs listening skill to listen to family's deep } \\
\text { feeling. } \\
\text { - A nurse needs to listen to families' disappointed } \\
\text { feeling. }\end{array}$ & $\begin{array}{l}\text { - Practice of care in } \\
\text { consideration of the } \\
\text { families' feelings }\end{array}$ \\
\hline $\begin{array}{l}\text { Promotion by nurses for family members to accept the } \\
\text { choice of transplantation is important. } \\
\text { - A nurse confirms transplantation even though family } \\
\text { members decided at least once. } \\
\text { - A nurse said that a family member could stop at any time. }\end{array}$ & $\begin{array}{l}\text { - A nurse support family member's choice. } \\
\text { - A nurse confirms decision of transplantation } \\
\text { repeatedly. } \\
\text { - A nurse guarantees of right to stop the } \\
\text { transplantation. }\end{array}$ & $\begin{array}{l}\text { - Support for decision } \\
\text { making considering } \\
\text { family members' } \\
\text { indecisiveness }\end{array}$ \\
\hline $\begin{array}{l}\text { - A nurse tried to communicate with family members, } \\
\text { Handling nurses for family care. } \\
\text { - Not all of the family members agree with transplantation. } \\
\text { or head nurse for support. }\end{array}$ & $\begin{array}{l}\text { - A nurse builds trusting relationships with family } \\
\text { members. } \\
\text { - Intention is not always agreed among family } \\
\text { members. } \\
\text { - Various kind of occupation get involved. }\end{array}$ & $\begin{array}{l}\text { - Construction of places } \\
\text { where family members } \\
\text { talk about their real } \\
\text { intention }\end{array}$ \\
\hline $\begin{array}{l}\text { - After transplantation, some of family members feel lonely } \\
\text { due to transplantation. } \\
\text { - Care from nurses to family members to live their lives } \\
\text { accepting the transplantation. }\end{array}$ & $\begin{array}{l}\text { - Family members feel lonely after transplantation, } \\
\text { wondering if the choice was right. } \\
\text { - Care for family after transplantation is needed. }\end{array}$ & $\begin{array}{l}\text { - Care for families to live } \\
\text { positively after } \\
\text { transplantation }\end{array}$ \\
\hline
\end{tabular}


making considering the family members' indecisiveness". Additionally, since family members have to deal with complicated matters, nurses thought it necessary for the "Construction of places where family members talk about their real intentions". Also, to consider family members after organ donation, they required "Care for families to live positively after transplantation". These categories suggest that mental and psychological care such that family members can express their intention including decision making and continuous care after transplantation were needed.

3) Required support for nurses in organ transplantation nursing (Table 4)

Nurses felt a lack of the number of nurses in organ transplantation and need of cooperation, such as a need to "Increase the number of nurses and cooperation with other departments". Moreover, they felt the importance of the "Education of the nursing practice specializing in transplantation". And since many nurses felt in a dilemma or discomfort, they required a "Chance to share their dilemma or discomfort", or "Mental care for nurses". These categories suggest nurses thought that increase of the numbers of nurses, education about transportation, chance to share dilemma, and mental care are needed.

\section{Discussion}

\section{1) Recognition of nurses for organ donation}

We chose the higher level of each category as themes. There are 3 themes: [Thoughts about the decision making of family members], [Thoughts about practical nursing in clinical situations], and [Thoughts about nursing or nurses].

Concerning the "Family's decision to respect the way of living", if family members talk about a member's hope for organ donation in daily life, or family members know the family's way of life, they could decide the organ donation

Table 4. Required support for nurses in organ donation nursing.

\begin{tabular}{|c|c|c|}
\hline Code & Subcategory & Category \\
\hline $\begin{array}{l}\text { Various kind of doctors treated a donor and gave some } \\
\text { instructions to nurses. } \\
\text { Increase of the number of nurses is required to care } \\
\text { because they had to care for patients in ICU as usual } \\
\text { care in addition to a donor. }\end{array}$ & $\begin{array}{l}\text { - A nurse needs way of cooperation with other } \\
\text { departments. } \\
\text { - Increase the number of nurses is required for physical } \\
\text { management and brain death judgment. }\end{array}$ & $\begin{array}{l}\text { - Increase of the number } \\
\text { of nurses and } \\
\text { cooperation with other } \\
\text { departments }\end{array}$ \\
\hline $\begin{array}{l}\text { - A nurse had a dilemma in raising physical functions } \\
\text { although she remained calm. } \\
\text { - Many nurses had uncomfortable feelings. }\end{array}$ & $\begin{array}{l}\text { - A nurse feels a dilemma in nursing. } \\
\text { - A nurse has uncomfortable feelings }\end{array}$ & $\begin{array}{l}\text { - Chance to share their } \\
\text { dilemma or discomfort }\end{array}$ \\
\hline $\begin{array}{l}\text { - Some nurses were shocked by transplantation. } \\
\text { - Some nurses had a sense of loss after transplantation. } \\
\text { - Nurses are relaxed when someone listened to their talk. }\end{array}$ & $\begin{array}{l}\text { - Some nurses had sense of loss or burnout after } \\
\text { transplantation. } \\
\text { - Nurses need to have someone to listen to their concerns. }\end{array}$ & - Mental care for nurses \\
\hline
\end{tabular}


easily. This category is different from previous studies such as heart death [3]. On the other hand, family members who do not mention such things or do not know a patient's will are categorized under "Suffering of family members in decision making". Tamura, Kataoka, Kodama, [10] showed the need of continuous care for families, includes decision making or mental support. Mills, Koulouglioti [11] suggests that it is crucial for nurses to communicate information clearly. Using specific terminology and explanation such as brain damage or brain death, can help the family come to terms with the patients' condition. In Japan, though physicians mainly explain the condition of patients, an additional explanation by a nurse using evidence or visual instruments will help the decision making of family members.

As for the "Influence of culture on decision making of body parts", family members refused to donate the eyes of a patient because the eye is needed to see family members in that world. Cai [12] showed that all Asian American participants expressed concerns about the afterlife, traditional burial sites, fear of mutilation, and the importance of the deceased to remain whole after death. This study supports that cultural difference and its influence on the decision making of organ donation in the present study.

"Taking responsibility while feeling conflicted" showed that some nurses had conflicting thoughts or religious views and struggled. West, Burr [13] demonstrated that family members of donors felt the nurse's attitude when the nurse felt conflicted. Thus, a nursing manager needs to know the nurse's attitude concerning organ transportation and plan continuous education about the role of nurses [14].

Concerning "Feeling of insufficiency for family care", a negative attitude toward family care was supported by the previous study [6] [15]. One of the reasons for a negative attitude was caused by the lack of knowledge about transplantation [16].

Education critical nurses about brain death and organ donation would increase the number of organ donation made each year [17].

\section{2) Requirement for family care in organ donation}

As for "Practice of care in consideration of families' feeling", this category suggests the importance for nurses to listen to the family's history, because family members may find meanings in organ donation and they are relieved [15]. Narrating families' history may be useful for their mental and psychological care. In narrative approach, Thomas, Reeve, Bingley, et al [18] said that people will find meanings in narratives.

Moreover, about "Support for decision making considering family member's indecisiveness", the family needs time to accept the patient's death and to decide on organ transplantation. Mills and Koulouglioti [19] said that families need time to accept the death of their relatives, and requesting an organ donation should not be done until the family members completely understand that brain death has occurred. In Japan, the importance of family care has been recognized [20]. 
Lastly, the category "Care for family to live positively after transplantation" showed the need of continuous care for families. Usually, families are apart from nurses after organ transplantation; however, grief care will be needed. Tanimizu, et al. [21] also suggest continuous care in kidney transplantation.

\section{3) Support for nurses involved in organ transplantation}

First, as for "Increase of the number of nurses and cooperation with other departments", nurses request the chance to learn more about organ transplantation. Kentish-Barnes, Duranteau, Montlahuc, et al. [22] showed that training nurses to have a good understanding of brain death and being able to convey that to the family in simple, clear terms is necessary for the critical care nurse. Moreover, Yokota, Ajimi, Nakahara [23] showed that physicians and nurses feel the burden of long work hours or strenuous effort during organ transplantation. Decreasing their burden may promote organ transplantation in Japan.

Some nurses felt a dilemma or conflict, so they needed "Chance to share their dilemma or discomfort". It is important for the critical care nurse to explore his or her feelings about organ donation, according to Xie, Ming, Ding, et al. [24]. Looking back at their own feelings or thoughts and talking to each other might promote nurses' mental growth. Related to the sharing of feelings by nurses, "Mental care to nurses" is required. Sharing feelings or thoughts may be useful to mental care. Death conferences also may be useful, according to Harding, et al. [25].

\section{Limitation of This Study and Future}

Since the number of participants who experienced organ transplantation was very few and we couldn't consider nursing experience or times. Thus it is hard to generalize the results in the present study. In a future study, we need to adjust the experience or times and increase the number of participants. Moreover, in future study, we make education program about organ donation and verify the utility of it.

\section{Conclusion}

Nurses recognized the importance of decision making, and felt an insufficiency for family care or dilemmas in organ donation nursing. To propose high quality of nursing and organ donation or transplantation, education about transplantation including family care, management about resolution of dilemma or mental health may be required.

\section{Conflicts of Interest}

The authors declare no conflicts of interest regarding the publication of this paper.

\section{References}

[1] Gao, W., Plummer, V. and Williams, A. (2017) Perioperative Nurses' Attitudes towards Organ Procurement: A Systematic Review. Journal of Clinical Nursing, 26, 
302-319. https://doi.org/10.1111/jocn.13386

[2] Japan Organ Transplant Network. The Number of Organ Transplantation in World. https://www.jotnw.or.jp/explanation/07/06/

[3] Laughlin, L.M., Neukirchinger, B. and Monks, J. (2020) Seeking Consent for Organ Donation: Process Evaluation of Implementing a New Specialist Requester Nursing Role. Journal of Advanced Nursing, 10. https://doi.org/10.1111/jan.14601

[4] Jawoniyi, O., Gormley, K., McGleenan, E. and Noble, H.R. (2017) Organ Donation and Transplantation: Awareness and Roles of Healthcare Professionals-A Systematic Literature View. Journal of Clinical Nursing, 27, e726-e738.

https://doi.org/10.1111/jocn.14154

[5] O'Leary, G.M. (2018) Deceased Donor Organ Donation: The Critical Care Nurse's Role. Nursing Critical Care, 13, 27-32. https://doi.org/10.1097/01.CCN.0000534920.55430.ba

[6] Nagano, K. and Kamizato, M. (2016) Challenge to the Difficulties Feeling and End of Life Care of Nurses at Organ Donation. Journal of Japan Academy of Critical Care Nursing, 12, 73-80. https://doi.org/10.11153/jaccn.12.3 73

[7] Hayashi, Y., Tanimizu, N. and Akazawa, C. (2013) A Nurse's Ethical Distress in Organ Transplantation Nursing-Through Analysis of a Case. Osaka Medical College Journal of Nursing Research, 3, 129-137.

[8] Kawakubo, K., Ojima, K. and Kotani, C. (2020) Nurses' Thoughts on Brain Death and Organ Transplantation after Enactment of the Revised Organ Transplant Law-Issues Emerged from the Current Situation. The Bulletin of Science of Nursing Research, 8, 67-77.

[9] Tannizu, Y. (2015) Start up Shitsutekikangokenkyu [Qualitative Nursing Research]. 2nd Edition, Gakken Medical Yujunsya, Tokyo. (In Japanese)

[10] Tamura, Y., Kataoka, M., Kodama, T. and Komori, T. (2018) Literature Review on Nursing Researches Focused on Psychological Aspect of Organ Transplant in Japan. Mie Nursing Journal, 20, 87-95.

[11] Daly, B.J. (2006) End of Life Decision Making, Organ Donation, and Critical Care Nurses. Critical Care Nurse, 26, 78-86. https://doi.org/10.4037/ccn2006.26.2.78

[12] Cai, Y. (2013) On the Impacts of Traditional Chinese Culture on Organ Donation. Journal of Medicine and Philosophy, 38, 149-159. https://doi.org/10.1093/jmp/jht007

[13] West, R. and Burr G. (2002) Why Families Deny Consent to Organ Donation. Australian Critical Care, 15, 27-32. https://doi.org/10.1016/S1036-7314(02)80041-8

[14] Vijayalakshmi, P., Nagarajaiah, Ramachandra and Math, S.B. (2015) Indian ICU Nurses' Perceptions of and Attitudes towards Organ Donation. British Journal of Nursing, 24, 694-697. https://doi.org/10.12968/bjon.2015.24.13.694

[15] Tamura, N. and Tsukamoto, N. (2018) A Survey of the Nursing Care for the Families of Brain-Dead Organ Donors-The Rate of Nurses' Recognition of Necessary Nursing Care Practices and the Rate of Implementation of Nursing Are Practices. Journal of Japanese Association for Emergency Nursing, 201, 10-19.

[16] Ushio, M. and Kawamoto, R. (2012) Factors Affecting Nurse's Dissatisfaction in Caring for Dying Patients Who Are Donors Affect Cardiac Death or Brain Death and Their Families. Journal of Japanese Association for Emergency Nursing, 15, $1-11$.

[17] Jawoniyi, O.O. and Gormley, K. (2015) How Critical Care Nurses' Roles and Education affect Organ Donation. British Journal Nursing, 4, 698-700. 
https://doi.org/10.12968/bjon.2015.24.13.698

[18] Thoams, C., Reeve, J., Bingley, A., Brown, J., Payne, S. and Lynch, T. (2009) Narrative Research Methods in Palliative Care Contexts: Two Case Studies. Journal of Pain and Symptom Management, 37, 788-796.

https://doi.org/10.1016/j.jpainsymman.2008.05.006

[19] Mills, L. and Koulouglioti, C. (2016) How Can Nurses Support Relatives of a Dying Patient with the Organ Donation Option. Nursing in Critical Care, 21, 214-224. https://doi.org/10.1111/nicc.12183

[20] Ito, M. (2019) Psychological Changes of Family Members from Truth Telling of Brain Death to Organ Donation. Sever Intensive Care, 18, 67-74.

[21] Tanimizu, N., Shuda, A., Imanishi, T., et al. (2014) The Existence of Experience and Frequency and Severity of Related Concerns of Ethical Issues in Nursing Practice Encountered in Organ Transplantation. Transplantation Proceeding, 46, 1029-1031. https://doi.org/10.1016/j.transproceed.2013.11.079

[22] Kentish-Barnes, N., Duranteau, J., Montlahuc, C., et al. (2017) Clinician's Perception and Experience of Organ Donation from Brain-Dead Patients. Critical Care Medicine, 45, 1489-1499. https://doi.org/10.1097/CCM.0000000000002581

[23] Yokota, M., Ajimi, Y. and Nakahara, S. (2018) Attitude, Perceived Burdens and Support Needs in Organ Transplantation after Brain Death: A Questionnaire Survey among Medical Staff. Journal of Japanese Association of Acute Medicine, 29, 209-217.

[24] Xie, J., Ming, Y., Ding, S., et al. (2017) Rising Need for Health Education among Renal Transplant Patients and Caregiving Competence in Care Providers. Progress in Transplantation, 27, 180-186. https://doi.org/10.1177/1526924817699962

[25] Harding, Y., Ando, M. and Yano, M. (2019) Literature Review on the Significance of Death Conferences for Nurses in Japan. Open Journal of Nursing, 9, 481-560. 